\title{
Gender differences in total cholesterol levels in patients with acute heart failure and its importance for short and long time prognosis
}

\author{
Lenka Spinarovaa ${ }^{a}$, Jindrich Spinar ${ }^{b}$, Jiri Vitovec ${ }^{a}$, Ales Linhart ${ }^{c}$, Petr Widimsky ${ }^{d}$, Marian Fedorco ${ }^{e}$, Filip Malek ${ }^{f}$ \\ Cestmir Cihalik ${ }^{\mathrm{g}}$, Roman Miklik ${ }^{\mathrm{b}}$, Ladislav Dusek ${ }^{\mathrm{h}}$, Klaudia Zidova ${ }^{\mathrm{a}}$, Jiri Jarkovsky' ${ }^{\mathrm{h}}$, Simona Littnerova ${ }^{\mathrm{h}}$, \\ Jiri Parenica ${ }^{\text {b\# }}$
}

\begin{abstract}
Aim. The purpose of this study was to evaluate whether there are gender differences in total cholesterol levels in patients with acute heart failure and if there is an association of this parameter with short and long time mortality. Methods. The AHEAD MAIN registry is a database conducted in 7 university hospitals, all with $24 \mathrm{~h}$ cath lab service, in 4 cities in the Czech Republic. The database included 4153 patients hospitalised for acute heart failure in the period 2006-2009. 2384 patients had a complete record of their total cholesterol levels. 946 females and 1437 males were included in this analysis. According to the admission total cholesterol levels, patients were divided into 5 groups: $<4.50$ $\mathrm{mmol} / \mathrm{I}$ (group A), 4.50-4.99 mmol/I (group B), $5.0-5.49 \mathrm{mmol} / \mathrm{I}$ (group C), $5.50-5.99 \mathrm{mmol} / \mathrm{l}$ (group D) and $>6.0 \mathrm{mmol} / /$ (group E). The median total cholesterol levels were 4.24 in males and 4.60 in females $(P<0.001)$. There were differences in the distribution of total cholesterol levels between men and women: group A 57.6 vs $45.0 \%$, group B 13.8 vs $16.3 \%$, group C 9.8 vs $12.5 \%$, group D 7.7 vs $11.4 \%$, group E 11.1 vs $14.8 \%$ respectively (all $P<0.001$ ). The median age of men was 68.7 vs 77.3 years in women $(P<0.001)$. In all total cholesterol categories women were older than men: group $A$ 77.7 vs 69.5 years, group B 78.6 vs 69.1 years, group C 77.3 vs 68.8 years, group D 76.8 vs 64.2 years, group E 75.6 vs 64.4 years (all $P<0.001$ ). For the calculation of long term mortality, the cohort was divided into three groups: total cholesterol levels below $4.50 \mathrm{mmol} / \mathrm{l}, 4.50-5.49 \mathrm{mmol} / \mathrm{l}$ and above $5.50 \mathrm{mmol} / \mathrm{l}$. The log rank test was used for the analysis. Results. There were no differences in hospital mortality between male and female in general (9.2 vs $10.8 \%, P<0.202)$, or in total cholesterol levels in subgroups. Total cholesterol levels were associated with in-hospital mortality $(P<0.002)$. In the long-term follow up (78 months) patients with total cholesterol levels below $4.5 \mathrm{mmol} / \mathrm{l}$ had the worst prognosis $(P<0.001)$. An independent influence of total cholesterol level on mortality and survival was confirmed in the multivariate model as well.

Conclusions. Women with acute heart failure had higher total cholesterol levels than men in all ages. There was a higher percentage of women with total cholesterol levels above $6 \mathrm{mmol} / \mathrm{l}$ and lower percentage in the group below $4.5 \mathrm{mmol} / \mathrm{l}$ than in men. In all, total cholesterol categories women were older than men. Total cholesterol levels are important for in- hospital mortality and long term survival of patients admitted for acute heart failure.
\end{abstract}

Key words: acute heart failure, AHEAD, cholesterol, gender, in-hospital mortality, prognosis

Received: September 6, 2011; Accepted with revision: January 24, 2012; Available online: February 17, 2012 http://dx.doi.org/10.5507/bp.2012.015

aInternal Cardioangiology Department, University Hospital St. Ann and Faculty of Medicine, Masaryk University Brno, Czech Republic
bInternal Cardiology Department University Hospital Brno and Faculty of Medicine Masaryk University Brno
'2 ${ }^{\text {nd }}$ Department of Internal Cardiovascular Medicine, First Medical Faculty, Charles niversity in Prague and General University Hospital
in Prague
${ }^{d}$ Cardiocenter, University Hospital Kralovske Vinohrady and the Third Faculty of Medicine, Charles University in Prague
eDepartment of Internal Medicine I - Cardiology, University Hospital Olomouc
'Department of Cardiology, Na Homolce Hospital, Prague
gInternal Cardiology Department, T. Bata Regional Hospital, Zlin
'Institute of Biostatistics and Analyses, Faculty of Medicine, Masaryk University Brno
"for the AHEAD investigators
Corresponding author: Lenka Spinarova, e-mail: Ienka.spinarova@fnusa.cz

\section{INTRODUCTION}

Acute heart failure (AHF) is a major and rapidly growing problem responsible for millions of hospitalisations worldwide ${ }^{1,2}$.

A prevalence of in-hospital mortality as high as $10 \%$ and re-hospitalisations $>50 \%$ within 1 year have been reported $^{3}$. In a prospective cohort of hospitalised patients with AHF (ADHERE), in-hospital mortality was 4\% $\left(\right.$ ref. $\left.^{4}\right)$; the Second EuroHeart Failure Survey (EHFS II) had an in-hospital mortality of $6.7 \%$ (ref. $\left.{ }^{1}\right)$.

The aetiology of AHF is mainly ischemic heart disease (IHD). More than $95 \%$ of patients with myocardial infarction with ST elevation are treated in the Czech Republic by primary percutaneous coronary intervention. Cholesterol is a risk factor for the development of atherosclerosis.

We hypothesised that total cholesterol levels in acute 
heart failure were significant in short and long term prognosis and that there were possible gender differences in this regard.

\section{MATERIAL AND METHODS}

The Acute Heart Failure Database (AHEAD) registry consisted of two independent parts. The AHEAD main registry includes consecutive patients in seven centres with a $24 \mathrm{~h}$ Cath Lab service and centralised care for patients with acute coronary syndromes (ACS) from a region of about 3 million inhabitants. The AHEAD network also includes five regional hospitals without a Cath Lab service.

The inclusion criteria for the database adhere to the European guidelines for HF. Hence, there must be signs and symptoms of HF; confirmed left-ventricular dysfunction (systolic or diastolic); and/or positive response to therapy ${ }^{5}$. The data were collated by experienced physicians - cardiologists.

In the majority of patients the laboratory data were available: minerals, urea, creatinine, glycaemia, transaminases, total cholesterol levels, triacylglycerols and blood count. Laboratory samples were collected on admission or on the $2^{\text {nd }}$ day of hospitalization in the morning on an empty stomach.

The AHEAD main registry included 4153 patients hospitalised at seven Cardiology Departments with Cath Lab facilities in four cities. The data were collected prospectively from September 2006 to October 2009 using a database accessible via the Internet website www.ahead. registry.cz, and were evaluated continuously (including in-hospital mortality). The long-term mortality was followed using the centralised database of the Ministry of Health of the Czech Republic and recent data from the year 2010. Written informed consent was obtained from all subjects. The study protocol complied with the Declaration of Helsinki, and was approved by the local
Ethics Committee of the Faculty Hospital Brno (Brno, Czech Republic).

\section{Statistical analyses}

Statistical analyses were done by the Institute of Biostatistics and Analyses of Masaryk University (Brno, Czech Republic). Standard summary statistics were used to describe primary data, absolute and relative frequencies, medians, the $5^{\text {th }}-95^{\text {th }}$ percentile range, arithmetic means, and standard deviation. The statistical significance of differences between groups of patients for continuous parameters was tested using the Mann-Whitney U test. The Fisher exact test and maximum likelihood $\mathrm{c}^{2}$ test were applied for analyses of differences in categorical data. The log rank test was used for the analysis of long term survival. The independent influence of total cholesterol level on mortality and survival was assessed using multivariate logistic regression and Cox proportional hazards model respectively.

Due to the large sample size, all statistical results were interpreted with respect to their clinical significance. Statistical analyses were undertaken using the SPSS 18.0.3 statistical package (SPSS, Chicago, IL, USA).

\section{RESULTS}

\section{Baseline characteristics}

Of 4153 patients, 526 (12.7\%) patients died during hospitalisation. The median length of hospitalisation was 7.1 days ( 5.5 days for those patients who died and 9.7 days for those who were discharged home) and was identical for males and females. Their baseline clinical characteristics and causes of acute heart failure is described in Table 1.

2384 patients had complete records for total cholesterol levels - 946 females and 1437 males were included in this analysis.

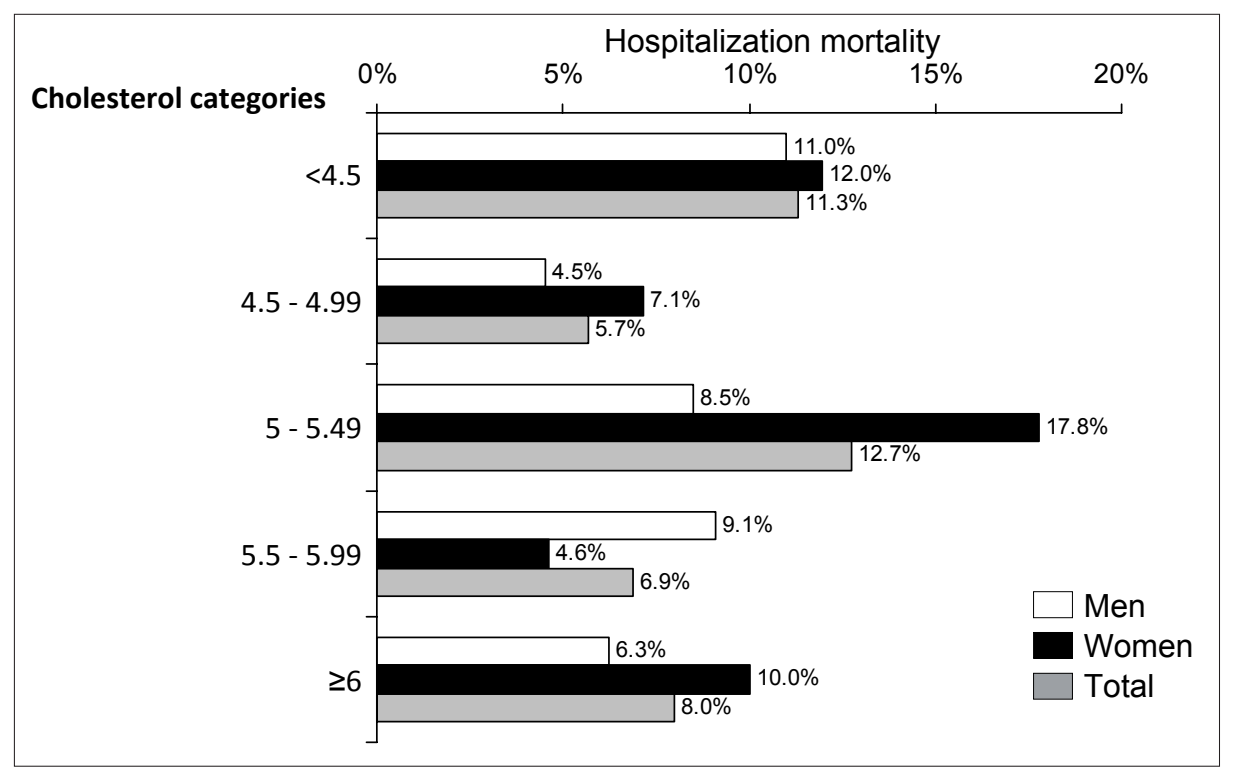

Fig. 1. Hospitalization mortality according to total cholesterol level. 
According to the admission total cholesterol levels, the patients were divided into 5 groups: $<4.50 \mathrm{mmol} / 1$ (group A), 4.50-4.99 mmol/1 (group B), 5.00-5.49 mmol/1 (group C), 5.50-5.99 mmol/1 (group D) and > $6.0 \mathrm{mmol} / \mathrm{l}$ (group E).

The median total cholesterol levels was $4.24 \mathrm{mmol} / 1$ in males and $4.60 \mathrm{mmol} / 1$ in females $(P<0.001)$. There were differences in the distribution of total cholesterol levels between men and women with more men in group A with the lowest level of total cholesterol and with more women in groups $\mathrm{B}, \mathrm{C}, \mathrm{D}, \mathrm{E}$ (all $P<0.001$ ) (Table 2). The median age of men was 68.7 vs 77.3 years in women $(P<0.001)$. In all total cholesterol categories women were older than men ( $P<0.001$ ) (Table 3 ).

For calculation of long-term mortality the cohort was divided into the three groups according to total choles- terol levels: below $4.500 \mathrm{mmol} / 1,4.50-5.40 \mathrm{mmol} / 1$ and above $5.40 \mathrm{mmol} / \mathrm{l}$. Log rank test was used for the analysis.

There were no differences in hospital mortality according to total cholesterol categories between men and women ( 9.2 vs $10.8 \%, P<0.202$ ), but total cholesterol levels were important for hospital mortality for both genders $(P<0.002)$ (Table 4) (Fig.1). In the long-term follow up (78 months) patients with total cholesterol level below 4.5 $\mathrm{mmol} / 1$ had the worst prognosis $(P<0.001)$ (Fig. 2$)$, men as well as women $(P<0.001)$ (Fig. 3$)$.

The independent influence of total cholesterol on mortality and survival was confirmed for both men and women also in the multivariate analysis when total cholesterol level below $4.5 \mathrm{mmol} / 1$ was combined with other predictors revealed in the univariate analysis (Table 5).

Table 1. Baseline characteristics of patients according to syndromes of acute heart failure.

\begin{tabular}{|c|c|c|c|c|c|c|c|c|}
\hline Patients characteristics & $\begin{array}{c}\text { Total }^{1} \\
(\mathrm{~N}=\mathbf{4 1 5 3})\end{array}$ & $\begin{array}{c}\text { ADHF } \\
(\mathrm{N}=2241)\end{array}$ & $\begin{array}{c}\text { Hypertensive } \\
\text { AHF } \\
(\mathrm{N}=179)\end{array}$ & $\begin{array}{c}\text { Pulmonary } \\
\text { oedema } \\
(\mathrm{N}=748)\end{array}$ & $\begin{array}{c}\text { Cardiogenic } \\
\text { shock } \\
(\mathrm{N}=600)\end{array}$ & $\begin{array}{l}\text { AHF with } \\
\text { high output } \\
(\mathrm{N}=132)\end{array}$ & $\begin{array}{l}\text { Right AHF } \\
(\mathrm{N}=156)\end{array}$ & $\boldsymbol{P}^{2}$ \\
\hline Female & $42.4 \%$ & $40.4 \%$ & $65.4 \%$ & $44.1 \%$ & $39.0 \%$ & $53.0 \%$ & $43.6 \%$ & $<0.001$ \\
\hline Age & $\begin{array}{c}73.8 \\
(49.3 ; 87.9)\end{array}$ & $\begin{array}{c}73.8 \\
(48.5 ; 87.6)\end{array}$ & $\begin{array}{c}74.8 \\
(49.3 ; 88.7)\end{array}$ & $\begin{array}{c}73.8 \\
(53.8 ; 88.3)\end{array}$ & $\begin{array}{c}74.3 \\
(50.3 ; 87.9)\end{array}$ & $\begin{array}{c}76.2 \\
(51.0 ; 91.1)\end{array}$ & $\begin{array}{c}65.8 \\
(35.3 ; 84.9)\end{array}$ & $<0.001$ \\
\hline$>70$ years & $60.0 \%$ & $59.9 \%$ & $61.5 \%$ & $62.6 \%$ & $60.0 \%$ & $70.5 \%$ & $41.0 \%$ & $<0.001$ \\
\hline De-novo HF & $58.3 \%$ & $52.6 \%$ & $74.3 \%$ & $58.4 \%$ & $68.7 \%$ & $63.6 \%$ & $77.6 \%$ & $<0.001$ \\
\hline ACS at admission & $36.2 \%$ & $33.1 \%$ & $0.0 \%$ & $40.8 \%$ & $61.3 \%$ & $7.6 \%$ & $25.6 \%$ & $<0.001$ \\
\hline NYHA III+IV & $43.2 \%$ & $48.8 \%$ & $34.0 \%$ & $43.2 \%$ & $27.2 \%$ & $37.2 \%$ & $29.5 \%$ & $<0.001$ \\
\hline Insignificant CAD & $13.9 \%$ & $15.8 \%$ & $22.3 \%$ & $12.4 \%$ & $5.5 \%$ & $13.6 \%$ & $15.4 \%$ & $<0.001$ \\
\hline Significant CAD & $51.0 \%$ & $51.5 \%$ & $16.2 \%$ & $55.0 \%$ & $65.0 \%$ & $20.6 \%$ & $32.1 \%$ & $<0.001$ \\
\hline CAD - unknown & 35.1 & $32.7 \%$ & $61.5 \%$ & $32.6 \%$ & $29.5 \%$ & $65.8 \%$ & $52.5 \%$ & $<0.001$ \\
\hline Hypertension & $73.1 \%$ & $70.4 \%$ & $94.3 \%$ & $80.8 \%$ & $72.1 \%$ & $68.0 \%$ & $60.7 \%$ & $<0.001$ \\
\hline Diabetes mellitus & $42.6 \%$ & $41.1 \%$ & $43.1 \%$ & $51.0 \%$ & $44.0 \%$ & $36.2 \%$ & $24.5 \%$ & $<0.001$ \\
\hline Previous MI & $32.1 \%$ & $31.6 \%$ & $26.4 \%$ & $36.8 \%$ & $36.0 \%$ & $23.6 \%$ & $11.3 \%$ & $<0.001$ \\
\hline Previous PCI or CABG & $29.5 \%$ & $29.0 \%$ & $3.4 \%$ & $28.7 \%$ & $45.2 \%$ & $9.1 \%$ & $25.0 \%$ & $<0.001$ \\
\hline $\mathrm{PM} / \mathrm{ICD} / \mathrm{CRT}$ & $12.2 \%$ & $14.5 \%$ & $8.4 \%$ & $11.6 \%$ & $7.5 \%$ & $9.8 \%$ & $6.4 \%$ & $<0.001$ \\
\hline COPD & $16.2 \%$ & $16.7 \%$ & $17.8 \%$ & $16.5 \%$ & $14.4 \%$ & $20.5 \%$ & $8.0 \%$ & 0.027 \\
\hline Stroke or TIA in history & $16.5 \%$ & $16.0 \%$ & $26.4 \%$ & $18.0 \%$ & $15.7 \%$ & $13.4 \%$ & $9.9 \%$ & 0.002 \\
\hline Atrial fibrillation & $26.5 \%$ & $28.3 \%$ & $19.0 \%$ & $21.4 \%$ & $19.7 \%$ & $73.5 \%$ & $19.2 \%$ & $<0.001$ \\
\hline Coronary angiography & $17.5 \%$ & $19.7 \%$ & $11.7 \%$ & $18.5 \%$ & $11.6 \%$ & $12.1 \%$ & $12.3 \%$ & $<0.001$ \\
\hline Systolic BP & $\begin{array}{c}135 \\
(80 ; 200)\end{array}$ & $\begin{array}{c}136 \\
(95 ; 195)\end{array}$ & $\begin{array}{c}198 \\
(140 ; 260)\end{array}$ & $\begin{array}{c}145 \\
(95 ; 218)\end{array}$ & $\begin{array}{c}110 \\
(55 ; 170)\end{array}$ & $\begin{array}{c}140 \\
(90 ; 180)\end{array}$ & $\begin{array}{c}110 \\
(60 ; 160)\end{array}$ & $<0.001$ \\
\hline Systolic BP $\leq 100$ & $15.6 \%$ & $10.0 \%$ & $0.0 \%$ & $8.7 \%$ & $44.4 \%$ & $15.2 \%$ & $36.1 \%$ & $<0.001$ \\
\hline Diastolic BP & $\begin{array}{c}80 \\
(50 ; 110)\end{array}$ & $\begin{array}{c}80 \\
(60 ; 110)\end{array}$ & $\begin{array}{c}100 \\
(70 ; 150)\end{array}$ & $\begin{array}{c}80 \\
(60 ; 120)\end{array}$ & $\begin{array}{c}65 \\
(30 ; 95)\end{array}$ & $\begin{array}{c}80 \\
(58 ; 112)\end{array}$ & $\begin{array}{c}70 \\
(34 ; 100)\end{array}$ & $<0.001$ \\
\hline Heart rate & $\begin{array}{c}90 \\
(54 ; 142)\end{array}$ & $\begin{array}{c}85 \\
(52 ; 140)\end{array}$ & $\begin{array}{c}93 \\
(55 ; 140)\end{array}$ & $\begin{array}{c}98 \\
(63 ; 141)\end{array}$ & $\begin{array}{c}90 \\
(45 ; 136)\end{array}$ & $\begin{array}{c}130 \\
(70 ; 170)\end{array}$ & $\begin{array}{c}90 \\
(49 ; 146)\end{array}$ & $<0.001$ \\
\hline Ejection fraction (\%) & $\begin{array}{c}37 \\
(16 ; 65)\end{array}$ & $\begin{array}{c}36 \\
(15 ; 65)\end{array}$ & $\begin{array}{c}55 \\
(30 ; 70)\end{array}$ & $\begin{array}{c}35 \\
(18 ; 60)\end{array}$ & $\begin{array}{c}30 \\
(12 ; 60)\end{array}$ & $\begin{array}{c}52 \\
(25 ; 70)\end{array}$ & $\begin{array}{c}57 \\
(25 ; 74)\end{array}$ & $<0.001$ \\
\hline Ejection fraction $\leq 30 \%$ & $37.9 \%$ & $38.3 \%$ & $5.6 \%$ & $42.8 \%$ & $52.6 \%$ & $10.1 \%$ & $12.2 \%$ & $<0.001$ \\
\hline
\end{tabular}

${ }^{1}$ Syndromes are not known for 97 patients. ACS - acute coronary syndrome, CAD - coronary artery disease, MI - myocardial infarction, PCI - percutaneous coronary intervention; CABG - coronary artery bypass graft, PM - pacemaker; ICD - Implantable cardiac defibrillator; CRT - Cardiac resynchronisation therapy; COPD - Chronic obstructive pulmonary disease; TIA - transient ischemic attack, BP -Blood pressure 


\section{DISCUSSION}

\section{Predictors of mortality}

AHEAD main registry is one of the largest national observational prospective databases of AHF. The register was suggested as a multicentre, prospective with long term follow-up of mortality ${ }^{6}$

In previous analyses (not yet published) using univariate logistic regression analyses we defined all parameters that were related to hospital and long-term mortality in patients without cardiogenic shock. After exclusion of cardiopulmonary resuscitation and use of adrenalin, according to the multivariate analyses, low levels of total cholesterol ( $<3 \mathrm{mmol} / \mathrm{l})$ were an independent predictive factor of higher in-hospital mortality (OR (95\% CI) 2.4 (1.4-4.2); $P<0.002)$. In the OPTIMIZE HF registry ${ }^{7}$, the strongest predictors of mortality in 48.612 patients were low SBP, hyponatraemia, high levels of creatinine and left-ventricular dysfunction ${ }^{8}$.

In the study of Arques, patients admitted for acute heart failure were prospectively included. By multivariate analysis, albumin $(P=0.0017), \mathrm{BNP}(P=0.016)$ and age $(P=0.03)$ were independent predictors of in-hospital death. Serum troponin I was predictive of in-hospital death ( $P=0.01$ ), as well as serum total cholesterol measured after stabilization $(P=0.004)$. However, these two variables no longer predicted outcome in multivariate models, unlike serum albumin and BNP (ref. ${ }^{9}$ ).

The study of Horwich investigated a relationship between lipid levels and in-hospital mortality in patients with acute HF. Baseline patient characteristics, treatment regimens, and in-hospital mortality were examined by total cholesterol (TC) levels $(\mathrm{mg} / \mathrm{dl})$ quartiles $(\mathrm{Q})$ as follows: Q1 ( TC < or =118), Q2 (TC 119-145), Q3 (TC 146-179), and Q4 (TC > or =180). Patients with lower TC were older and had a higher prevalence of ischemic heart disease. In-hospital mortality in TC Q1 to Q4 was $3.3 \%, 2.5 \%$, $2.0 \%$, and $1.3 \%$, respectively $(P<0.0001)$. On multivariable adjusted analyses, each $10-\mathrm{mg} / \mathrm{dl}(0.26 \mathrm{mmol} / 1)$ increase in TC level was associated with $4 \%$ decreased risk of inhospital mortality (odds ratio 0.96, 95\% CI 0.93-0.98).

In patients hospitalized with HF, lower TC levels independently predicted increased in-hospital mortality risk ${ }^{10}$ Similar results as in our study were confirmed in the prospective study of Rauchaus et al. They studied the relationship between total cholesterol and survival in patients with chronic heart failure. Increasing total cholesterol was a predictor of survival, independent of age, etiology of

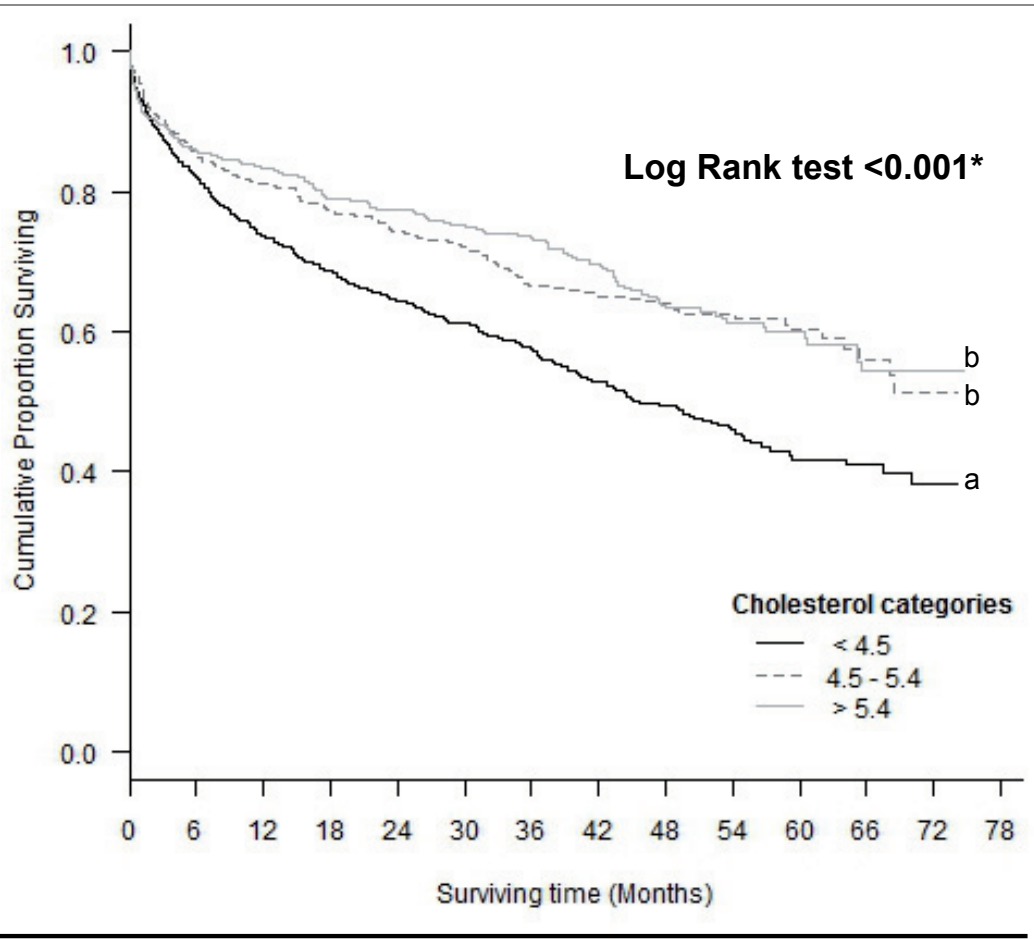

\begin{tabular}{|c|c|c|c|}
\hline & \multicolumn{3}{|c|}{ Cholesterol categories } \\
\hline & $<4.5$ & $4.5-5.4$ & $>5.4$ \\
\hline & $\mathrm{N}=1038(53.1 \%)$ & $\mathrm{N}=492(25.2 \%)$ & $\mathrm{N}=423(21.7 \%)$ \\
\hline 1 year survival & $73.8(71.1 ; 76.5)$ & $83.7(80.1 ; 87.2)$ & $81.4(78.0 ; 84.9)$ \\
\hline 3 years survival & $57.7(54.5 ; 60.8)$ & $73.6(69.3 ; 78.0)$ & $66.7(62.2 ; 71.1)$ \\
\hline 5 years survival & $41.9(37.4 ; 46.4)$ & $60.0(54.4 ; 65.7)$ & $60.3(55.0 ; 65.7)$ \\
\hline
\end{tabular}

a. b. $\mathrm{c}$ - the same letters denotes groups of patients which are not statistically significantly different (log rank test)

Fig. 2. Long-term survival for discharged patients according to total cholesterol level. 
heart failure, ejection fraction of left ventricle or exercise capacity. Receiver-operating characteristic curves demonstrated the cut-off value $<5.2 \mathrm{mmol} / 1$ as being the best predictor of 12 month mortality. The chance of survival increased $25 \%$ for each $\mathrm{mmol} / 1$ increment in total cholesterol ${ }^{11}$

It may be that higher total cholesterol represents a greater metabolic reserve to deal with heart failure syndrome. There might be a specific protective role for lipoproteins in chronic heart failure and also in long-term follow up of acute heart failure patients. Total cholesterol is still likely to be proatherogenic, but the risk associated with this mechanism is unlikely to affect prognosis over the relatively short follow up. If total cholesterol limits the production of harmful cytokines (TNFR-1), then the higher levels of total cholesterol might have a strongly positive effect on survival ${ }^{11}$.

Conventional risk factors such as obesity, hypertension and hypercholesterolemia are associated with increased risk of developing chronic heart failure and mortality in the general population. In marked contrast to the general population, a higher body mass index, increased serum total cholesterol level and higher blood pressure are strongly correlated with decreased morbidity and mortality in heart failure ${ }^{12,13}$. These paradoxical observations have been referred to as reverse epidemiology ${ }^{14}$. As the heart failure population has a greater mortality risk than that in general population, the long- term effects of these factors may be overwhelmed by the short- term effects of other factors on heart failure. Another phenomenon should be taken in acount, known as reverse causation. This indicates that low blood pressure, BMI or total serum cholesterol are not etiologically linked to a higher mortality in heart failure patients, but they are merely the markers of poor outcome ${ }^{14}$

\section{Gender differences in cholesterol level}

In the study of Spinar total cholesterol levels were measured at public places (mostly department stores) from 2005 to 2008. No significant difference between genders in total cholesterol levels were found. A smaller proportion of women than men had total cholesterol below $5 \mathrm{mmol} / 1$ (45.2 vs $53.0 \%$ ). Total cholesterol levels rise with age in both genders, stagnate at a certain point and subsequently decline. There was a significant difference in this between men and women - the levels start to stagnate at the age of 50 in men and beyond the age 65-70 in women. The levels fall with increasing age in both genders after the age of 65 . Total cholesterol levels were statistically significantly higher in women over 55 years. This difference was retained to the advanced age of $>75$ years $^{15}$. It is generally accepted that menopause leads to hormonal, metabolic and lipid profiles changes. Agrinier et al. conducted a meta-analysis of 10 cross-over and 9 long-term clinical trials examining lipid levels in postmenopausal women and showed that these women have higher total cholesterol, LDL cholesterol and trigylcerides and that these changes persist even after adjustment for age. Interestingly, these differences did not affect hormonal treatment for estrogen ${ }^{16}$.

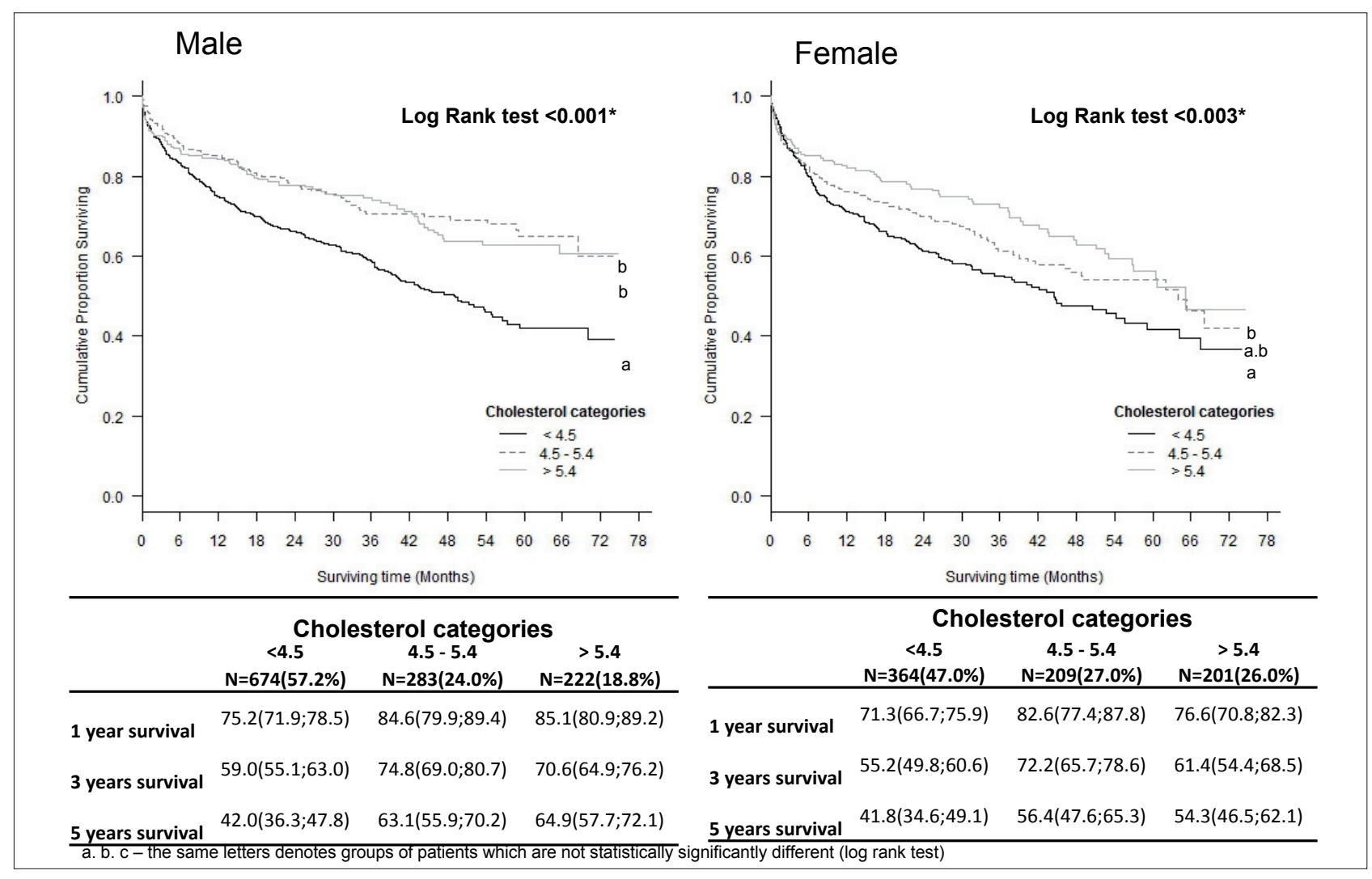

Fig. 3. Long-term survival for discharged patients according to the total cholesterol level and gender. 
WHILA - The Womens Health in the Lund Area (in Sweden) study examined 6908 women aged 50-59 years. These women were divided into premenopausal (PM), postmenopausal without hormone therapy (PM0) and postmenopausal with hormone therapy (PMT). Total cholesterol increased with age both in PM0 $(P<0.001)$ and the PMT $(P<0.001)$, similarly increased LDL cholesterol in the PM0 $(P<0.001)$ and slightly less for PMT $(P<0.007)$. The number of women with total cholesterol $>$ $7.0 \mathrm{mmol} / 1$ and triglycerides $>2.0 \mathrm{mmol} / 1$ decreased with age in PM, but significantly increased both the PM0 and PMT. Total cholesterol increased with age in all groups, but due to the rise in HDL cholesterol in PM and due to LDL cholesterol in PM0 and PMT (ref. ${ }^{17}$ ). In an multiethnic population of 2556 persons aged $65-103$ years there was observed a relationship between total cholesterol and overall mortality. People in the lowest total cholesterol quartile had a 2-fold higher risk of death than those in the highest quartile, and this was expressed most in whites and less in Hispanics. High total cholesterol seems not to be a cardiovascular risk factor for persons $>65$ years and conversely low total cholesterol is associated with higher mortality ${ }^{18}$.

Our study confirms the same results: older women have higher total cholesterol than men of same age but lower risk of mortality.

\section{Study limitation}

Our presented results are only from hospitals with Cath Lab service (AHEAD main), results from regional hospitals participating in AHEAD network were not included. This could lead to a higher contribution of patients with ACS and high percentage of patients with performed coronary angiography and PCI during hospitalization.

Table 2. Proportion of patients according to the total cholesterol categories and gender.

\begin{tabular}{|c|c|c|c|c|}
\hline & $\begin{array}{l}\text { All patients } \\
(\mathrm{N}=2384)\end{array}$ & $\begin{array}{l}\text { Women }^{1} \\
(\mathrm{~N}=946)\end{array}$ & $\begin{array}{c}\text { Men }^{1} \\
(\mathrm{~N}=1437)\end{array}$ & $P^{2}$ \\
\hline \multicolumn{5}{|l|}{ Total cholesterol level } \\
\hline & $4.40(2.50 ; 6.80)$ & $4.60(2.70 ; 6.95)$ & $4.24(2.37 ; 6.67)$ & $<0.001 *$ \\
\hline \multicolumn{5}{|c|}{ Total cholesterol categories } \\
\hline Group A: $<4.50$ & $1253(52.6 \%)$ & $426(45.0 \%)$ & $827(57.6 \%)$ & $<0.001 *$ \\
\hline Group B: 4.50-4.99 & $353(14.8 \%)$ & $154(16.3 \%)$ & $199(13.8 \%)$ & \\
\hline Group C: $5.00-5.49$ & $259(10.9 \%)$ & $118(12.5 \%)$ & $141(9.8 \%)$ & \\
\hline Group D: 5.50-5.99 & $218(9.1 \%)$ & $108(11.4 \%)$ & $110(7.7 \%)$ & \\
\hline Group E: $\geq 6.00$ & $300(12.6 \%)$ & $140(14.8 \%)$ & $160(11.1 \%)$ & \\
\hline
\end{tabular}

${ }^{1}$ Continuous variables are expressed as median, $5^{\text {th }}$ and $95^{\text {th }}$ percentile, categorical variables as percentage proportion within gender group

${ }^{2}$ Mann-Whitney U test for total cholesterol level and Chi-square test for total cholesterol categories for testing differences between genders;

*statistically significant

Table 3. Age of patients according to the total cholesterol level and gender.

\begin{tabular}{|c|c|c|c|c|}
\hline Age & All patients ${ }^{1}$ & Women $^{1}$ & $\operatorname{Men}^{1}$ & $P^{2}$ \\
\hline \multicolumn{5}{|c|}{ Total cholesterol categories } \\
\hline Group A: $<4.50$ & $72.8(47.4 ; 87.0)$ & $77.7(53.8 ; 89.5)$ & $69.5(44.4 ; 85.1)$ & $<0.001 *$ \\
\hline Group B: $4.50-4.99$ & $72.6(53.5 ; 87.3)$ & $78.6(55.9 ; 88.4)$ & $69.1(48.7 ; 84.8)$ & $<0.001 *$ \\
\hline Group C: $5.00-5.49$ & $72.8(52.3 ; 85.3)$ & $77.3(54.3 ; 86.3)$ & $68.8(51.8 ; 83.1)$ & $<0.001 *$ \\
\hline Group D: 5.50 - 5.99 & $70.9(45.5 ; 85.9)$ & $76.8(50.0 ; 87.8)$ & $64.2(43.2 ; 83.9)$ & $0.004^{*}$ \\
\hline Group E: $\geq 6.00$ & $69.4(47.4 ; 85.8)$ & $75.6(54.8 ; 86.9)$ & $64.4(43.6 ; 83.6)$ & $<0.001^{*}$ \\
\hline Together & $72.0(48.9 ; 86.4)$ & $77.3(54.4 ; 88.2)$ & $68.7(45.3 ; 84.8)$ & $<0.001 *$ \\
\hline
\end{tabular}

${ }^{1}$ Age is expressed by median, $5^{\text {th }}$ and $95^{\text {th }}$ percentile.

${ }^{2}$ Mann-Whitney U test for testing differences in age between men and women within total cholesterol level group; *statistically significant 


\section{CONCLUSION}

The AHEAD main registry provides up-to-date information on demographic characteristics and the underlying conditions of AHF patients as well as the aetiology, investigation, treatment and prognosis of AHF in a country with centralized care for ACS and with a high percentage of patients with performed angiography and coronary revascularization.

Women with acute heart failure have higher total cholesterol levels than men. There is a higher percentage of women with total cholesterol above $6 \mathrm{mmol} / \mathrm{l}$ and lower percentage in the group below $4.5 \mathrm{mmol} / 1$ than in men. In all total cholesterol categories women were older than men. Total cholesterol levels influence the in-hospital mortality and are predictive for long term mortality of patients admitted for acute heart failure. The independent influence of total cholesterol level on mortality and survival was confirmed in the multivariate model. Patients with cholesterol below $4.50 \mathrm{mmol} / 1$, irrespective of gender, have the worst prognosis.

Table 4. Hospitalization mortality according to the total cholesterol categories and gender.

\begin{tabular}{|c|c|c|c|c|}
\hline & All patients ${ }^{1}$ & Women $^{1}$ & $\operatorname{Men}^{1}$ & $P^{2}$ \\
\hline \multicolumn{5}{|c|}{ Total cholesterol categories } \\
\hline Group A: $<4.50$ & $142(11.3 \%)$ & $51(12.0 \%)$ & $91(11.0 \%)$ & 0.610 \\
\hline Group B: 4.50 - 4.99 & $20(5.7 \%)$ & $11(7.1 \%)$ & $9(4.5 \%)$ & 0.293 \\
\hline Group C: $5.00-5.49$ & $33(12.7 \%)$ & $21(17.8 \%)$ & $12(8.5 \%)$ & $0.026^{*}$ \\
\hline Group D: $5.50-5.99$ & $15(6.9 \%)$ & $5(4.6 \%)$ & $10(9.1 \%)$ & 0.189 \\
\hline Group E: $\geq 6.00$ & $24(8.0 \%)$ & $14(10.0 \%)$ & $10(6.3 \%)$ & 0.233 \\
\hline Together & $234(9.8 \%)$ & $102(10.8 \%)$ & $132(9.2 \%)$ & 0.202 \\
\hline$P^{3}$ & $0.002 *$ & $0.009 *$ & $0.023^{*}$ & \\
\hline
\end{tabular}

${ }^{1}$ Mortality is expressed by number and percentage proportion within gender-total cholesterol level-group

${ }^{2}$ Chi-square test for total cholesterol categories for testing differences in proportion of deceased patients between genders; ${ }^{*}$ statistically significant ${ }^{3}$ Chi-square test for testing differences in proportion of deceased patients between total cholesterol categories within men and women; ${ }^{*}$ statistically significant

Table 5. Total cholesterol level in multivariate model for mortality or long term survival prediction.

\begin{tabular}{|c|c|c|c|c|}
\hline & \multicolumn{2}{|l|}{ Women } & \multicolumn{2}{|c|}{ Men } \\
\hline \multicolumn{5}{|l|}{ Hospitalization mortality $^{1}$} \\
\hline & OR $(95 \% \mathrm{CI})$ & $P$ & OR $(95 \% \mathrm{CI})$ & $P$ \\
\hline Total cholesterol $<4.5 \mathrm{mmol} / 1$ & $1.82(1.01 ; 3.28)$ & 0.045 & $1.57(1.03 ; 2.38)$ & 0.036 \\
\hline Age $>70 \mathrm{yrs}$ & $2.20(1.09 ; 4.44)$ & 0.028 & $2.35(1.57 ; 3.50)$ & $<0.001$ \\
\hline Cardiogenic shock & $7.83(4.26 ; 14.39)$ & $<0.001$ & $1.96(1.73 ; 2.22)$ & $<0.001$ \\
\hline Invasive ventilation & $6.79(3.65 ; 12.61)$ & $<0.001$ & - & \\
\hline Creatinine $>120$ umol/1 & $1.58(0.88 ; 2.83)$ & 0.122 & - & \\
\hline $\mathrm{Na}>130 \mathrm{mmol} / \mathrm{l}$ & - & & $3.06(1.60 ; 5.87)$ & $<0.001$ \\
\hline \multicolumn{5}{|l|}{ Long term survival $^{2}$} \\
\hline & $\operatorname{HR}(95 \% \mathrm{CI})$ & $P$ & $\operatorname{HR}(95 \% \mathrm{CI})$ & $P$ \\
\hline Total cholesterol $<4.5 \mathrm{mmol} / 1$ & $1.30(1.02 ; 1.66)$ & 0.037 & $1.43(1.14 ; 1.80)$ & 0.002 \\
\hline Age $>70$ yrs & $1.54(1.15 ; 2.07)$ & 0.004 & $1.82(1.44 ; 2.28)$ & $<0.001$ \\
\hline Creatinine max. > 145 umol/1 & - & & $2.16(1.73 ; 2.71)$ & $<0.001$ \\
\hline Haemoglobin: $\leq 120 / 130 \mathrm{~g} / \mathrm{dl}$ & - & & $1.43(1.14 ; 1.80)$ & 0.002 \\
\hline Diabetes mellitus & $1.58(1.23 ; 2.04)$ & $<0.001$ & $1.21(0.97 ; 1.50)$ & 0.094 \\
\hline Previous stroke or TIA & $1.35(0.99 ; 1.84)$ & 0.054 & $1.46(1.11 ; 1.94)$ & 0.008 \\
\hline
\end{tabular}

${ }^{1}$ odds ratio supplemented by $95 \%$ confidence interval and its significance is based on logistic regression

${ }^{2}$ hazard ratio supplemented by $95 \%$ confidence interval and its significance is based on Cox proportional hazards model 


\section{ACKNOWLEDGEMENTS}

The study was supported by research project VVZ MŠMT 0021622402 of the Czech Ministry of Education and grant IGA MZ 9880-3 of the Czech Ministry of Health.

We thank the study investigators for their contribution to the study.

Participating centres and investigators: Czech Republic: University Hospital Brno, Brno: Marian Felsoci, Katerina Horakova, Ondrej Ludka; University Hospital St. Anne’s, Brno: Tereza Mikušová; Cardiocenter, University Hospital Kralovske Vinohrady, Prague: Filip Rohac, Richard Fojt; General University Hospital in Prague, Prague: Jan Belohlavek, Na Homolce Hospital, Prague: Petr Ostadal, Andreas Kruger; University Hospital Olomouc: Jan Vaclavik, David Vindis; T. Bata Regional Hospital Zlin: Zdenek Coufal, Petr Hrdy, Stanislava Penasova, Miroslav Bambuch.

\section{CONFLICT OF INTEREST STATEMENT}

Author's conflict of interest diclosure: None of the authors has any proprietary interest.

\section{REFERENCES}

1. Nieminen MS, Brutsaert D, Dickstein $K$, Drexler $H$, Follath $F$, Harjola VP, Hochadel M, Komajda M, Lassus J, Lopez-Sendon JL, Ponikowsk P, Tavazzi L. EuroHeart Failure Survey II (EHFS II): a survey on hospitalized acute heart failure patients: description of population. European Heart Journal 2006;27(22):2725-36.

2. WRITING GROUP, Lloyd-Jones D, Adams RJ, Brown TM, Carnethon M, Dai S, De Simone G, Ferguson TB, Ford E, Furie K, Gillespie C, Go A, Greenlund K, Haase N, Hailpern S, Ho PM, Howard V, Kissela B, Kittner S, Lackland D, Lisabeth L, Marelli A, McDermott MM, Meigs J, Mozaffarian D, Mussolino M, Nichol G, Roger VL, Rosamond W, Sacco R, Sorlie P, Stafford R, Thom T, Wasserthiel-Smoller S, Wong ND, Wylie-Rosett J, on behalf of the American Heart Association Statistics Committee and Stroke Statistics Subcommittee. Executive Summary: Heart Disease and Stroke Statistics-2010 Update: A Report From the American Heart Association. Circ 2010;121(7):948-54.

3. Bueno H, Ross JS, Wang $Y$, Chen J, Vidán MT, Normand SL, Curtis JP, Drye EE, Lichtman JH, Keenan PS, Kosiborod M, Krumholz HM. Trends in Length of Stay and Short-term Outcomes Among Medicare Patients Hospitalized for Heart Failure, 1993-2006. JAMA:The Journal of the American Medical Association 2010;303(21):2141-7.

4. Abraham WT, Adams KF, Fonarow GC, Costanzo MR, Berkowitz RL, LeJemtel TH, Cheng ML, Wynne J, the ADHERE Scientific Advisory Committee, and the ADHERE Study Group. In-Hospital Mortality in Patients With Acute Decompensated Heart Failure Requiring Intravenous Vasoactive Medications: An Analysis From the Acute
Decompensated Heart Failure National Registry (ADHERE). J Am Coll Cardiol 2005;46(1):57-64.

5. Nieminen MS, Böhm M, Cowie MR, Drexler H, Filippatos GS, Jondeau G, Hasin Y, Lopez-Sendon J, Mebazaa A, Metra M, Rhodes A, Swedberg K, Priori SG, Garcia MAA, Blanc JJ, Budaj A, Cowie MR, Dean V, Deckers J, Burgos EF, Lekakis J, Lindahl B, Mazzotta G, Morais J, Oto A, Smiseth OA, Garcia MAA, Dickstein K, Albuquerque A, Conthe P, Crespo-Leiro M, Ferrari R, Follath F, Gavazzi A, Janssens U, Komajda M, Morais J, Moreno R, Singer M, Singh S, Tendera M, Thygesen $\mathrm{K}$. Executive summary of the guidelines on the diagnosis and treatment of acute heart failure. Eur Heart J 2005;26(4):384-416.

6. Drolet BC, Johnson KB. Categorizing the world of registries. J Biomed Informatics 2008;41(6):1009-20.

7. Rossi JS, Flaherty JD, Fonarow GC, Nunez E, Gattis Stough W, Abraham WT, Albert NM, Greenberg BH, O'Connor CM, Yancy CW, Young JB, Davidson CJ, Gheorghiade M. Influence of coronary artery disease and coronary revascularization status on outcomes in patients with acute heart failure syndromes: A report from OPTIMIZE-HF (Organized Program to Initiate Lifesaving Treatment in Hospitalized Patients with Heart Failure). Eur J Heart Fail 2008;10(12):1215-23.

8. Abraham WT, Fonarow GC, Albert NM, Stough WG, Gheorghiade M, Greenberg BH, O'Connor CM, Sun JL, Yancy CW, Young JB, on behalf of the OPTIMIZE-HF Investigators and Coordinators. Predictors of InHospital Mortality in Patients Hospitalized for Heart Failure: Insights From the Organized Program to Initiate Lifesaving Treatment in Hospitalized Patients With Heart Failure (OPTIMIZE-HF). J Am Coll Cardiol 2008;52(5):347-56.

9. Arques S, Pieri B, Biegle G, Roux E, Gelisse R, Jauffret B. Comparative value of $B$-type natriuretic peptide and serum albumin concentration in the prediction of in-hospital mortality in elderly patients admitted for acute severe heart failure.Ann Cardiol Angeiol (Paris) 2009; 58(5):279-83.

10. Horwich TB, Hernandez AF, Dai D, Yancy CW, Fonarow GC. Cholesterol levels and in-hospital mortality in patients with acute decompensated heart failure. Am Heart J 2008; 156(6):1170-6.

11. Rauchhaus M., Clark AL, Doehner W, Davos C, Bolger A, Sharma R, Coats AJS, Anker SD. The relationship between cholesterol and survival in patients with chronic heart failure. J Am Coll Cardiol 2003;42:1933-40.

12. Horwich TB, Fonarow GC. The impact of obesity on survival in patients with heart failure. Heart Fail Monit 2002;3:8-14

13. Horwich TB, Hamilton MA, MacLellan WR,Fonarow GC. Low total cholesterol is associated with marked increase in mortality in advanced heart failure. J Card Fail 2002;8:216-24.

14. Kalantar-Zadeh K, Block G, Horwich T, Fonarow GC. Reverse epidemiology of conventional cardiovascular risk factors in patients with chronic heart failure. J Am Coll Cardiol 2004;43(8):1439-44.

15. Špinar J, Ludka O, Šenkyříková M, Vítovec J, Špinarová L, Dušek L. Hladiny cholesterolu v závislosti na věku. Vnitřní lékařství 2009;55(9):724-9.

16. Agrinier N, Cournot M, Ferrieres J. Dyslipdemia in women after 50: Age, menopause or both. Annales de cardiologie et d angeiologie 2008;58:159-64.

17. Nerbrand C, Lidfeldt J, Nyberg P, Schustén B, Samsioe G. Serum lipids and lipoproteins in relation to endogenous and exogenous female sex steroids and age. The Womens Health in the Lund Area (WHILA) study. Maturitas 2004:48;161-9.

18. Akerblom JL, Costa R, Luchsinger JA,Manly JJ, Tang MX, Lee JH, Mayerex R, Schupf N. Relation of plasma lipids to all-cause mortality in caucasions, African-americans and hispanic elders. Age and Aging 2007;37(2):207-13. 